\title{
POLA ALIH TUTUR PADA PODCAST DEDDY COBUZIER
}

\author{
Syarif Hidayatullah, Rini Damayanti, Fransisca Dwi Harjanti \\ Pendidikan Bahasa Indonesia, Universitas Wijaya Kusuma Surabaya \\ rinidamayanti_fbs@uwks.ac.id
}

\begin{abstract}
ABSTRAK
Di era perkembangan zaman yang semakin maju, pola alih tutur dalam percakapan khususnya dalam percakapan sehari-hari semakin banyak dijumpai dalam berbagai media yang semakin maju mengikuti era saat ini. Youtube merupakan platform berbagi video yang paling terkemuka. Youtube menyajikan berbagai konten yang menarik dan bisa dipilih susai selera tiap pengguna, satu diantaranya yaitu konten Podcast. Podcast menyajikan wawancara atau obrolan antara beberapa individu. Podcast merupakan pembahasan yang menjadi fokus pola alih tutur pengambilan alih giliran bicara. Podcast yang digunakan yaitu Podcast Deddy Corbuzier Episode Natalan Bareng Penista. Dalam Podcast tersebut terdapat tiga orang narasumber yaitu $\mathrm{dc}$, ck, dan tm. Penelitian ini termasuk ke dalam penelitian kualitatif. Peneliti bertindak sebagai human instrument. Data penelitian merupakan kutipan percakapan dalam Podcast milik ketiga narasumber yang menggunakan beberapa teknik pengambilan alih giliran bicara. Sesuai dengan tujuan penelitian, penelitian ini memperoleh berbagai macam penggunaan teknik pengambilan alih giliran bicara dalam Podcast Deddy Corbuzier Episode Natalan Bareng Penista!! Coki Pardede \& Tretan Muslim. Pada penelitian ini, disimpulkan teknik pengambilan alih giliran bicara terbagi ke dalam enam bentuk yaitu memperoleh, mencuri, merebut, mengganti, menciptakan, dan melanjutkan.
\end{abstract}

Kata Kunci : podcast, alih tutur

\section{PENDAHULUAN}

Dalam konteks tata bahasa, Wacana merupakan suatu gramatikal tertinggi dalam unit bahasa. Menurut Tarigan (2009:19) wacana adalah satuan bahasa terlengkap dan tertinggi atau terbesar di atas kalimat atau klausa dengan koherensi dan kohesi tinggi yang berkesinambungan yang mempunyai awal dan akhir nyata disampaikan secara lisan atau tertulis. Dalam aliran linguistik terdapat analisis wacana. Analisis wacana (discourse analysis) merupakan satu diantara cabang linguistik yang mengkaji satuan lingual yang berada di atas kalimat. Analisis wacana mengkaji wacana, baik dari segi internal maupun eksternal. Dari segi internal, wacana dikaji dari jenis, struktur, dan hubungan bagian-bagiannya. Dari segi eksternal, wacana dikaji dari keterkaitan wacana itu dengan pembicara, hal yang dibicarakan, dan mitra bicara (Baryadi, 2002: 3,4).

Data dalam analisis wacana selalu berupa teks, baik teks lisan maupun tertulis. Teks di sini mengacu pada bentuk transkripsi rangkaian kalimat atau ujaran. Teks lisan itu sendiri biasa di sebut dengan wacana lisan. Wacana lisan adalah wacana yang disampaikan secara lisan atau langsung dengan bahasa verbal (Mulyana, 2005:51). Kalimat dalam wacana lisan cenderung kurang terstruktur (gramatikal) apabila dibandingkan bahasa tulis. Bahasa lisan cenderung berisi beberapa kalimat yang tidak lengkap, bahkan sering hanya berupa urutan kata 
yang membentuk frase. Wacana lisan juga mencakup pola alih tutur dalam percakapan.

Alih tutur (turn taking) dalam suatu percakapan sangat penting, karena peralihan tutur ini akan menimbulkan pergantian peran peserta dalam percakapan. Peran tersebut terbagi penjadi penutur pertama (pembicara) dan mitra tutur (pendengar atau lawan bicara). Pengambilan alih giliran bicara tidak diatur secara resmi, akan tetapi hal itu terikat dengan aturan tidak tertulis atau disesuaikan dengan norma-norma yang berlaku dalam masyarakat. Orang-orang yang melanggar aturan tidak tertulis ini dianggap tidak sopan, seperti memonopoli pembicaraan, ingin selalu menang dalam pembicaraan, tidak memberi peserta lain kesempatan dalam berbicara, beberapa hal tersebut dianggap telah melanggar norma atau kaidah dalam berbicara.

Percakapan melibatkan beberapa orang di dalamnya, meskipun melibatkan beberapa orang, penyebaran dalam penyebaran dalam mengambil peran pembicara bukanlah secara acak. Peralihan peran pembicara mengikuti pola tertentu yaitu mengikuti suatu kaidah yang disebut kaidah alih tutur. Adapun pengelompokan cara pengambilan alih giliran bicara agar kegiatan peristiwa tutur berlangsung baik yaitu dengan teknik (a) memperoleh, (b) mencuri, (c) merebut, (d) menciptakan, (e) mengganti, (f) melanjutkan (Rani, 2006:213).

Dewasa ini, berbagai macam wacana lisan maupun tertulis dapat diakses dengan mudah, hal tersebut sesuai dengan kebutuhan manusia akan informasi yang semakin meningkat, sehingga menuntut perkembangan teknologi yang semakin maju dapat diakses kapanpun dan dimanapun. Pada umumnya manusia memperoleh informasi dari media cetak, televisi dan radio, hal tersebut membuat informasi terbatas. Namun seiring berkembangnya teknologi dan zaman, informasi kini dapat diakses kapanpun dan dimanapun dengan adanya media digital atau online. Manusia dapat mengakses berita lisan maupun tertulis yang lebih bersifat universal tanpa batas, bahkan berita lama yang sulit ditemukan dapat diakses dengan mudah. Beberapa diantaranya media online yang sering diakses yaitu Google, Twitter, Instagram, YouTube dan sebagaiannya.

Dalam berkomunikasi, seorang penutur dituntut untuk mengetahui situasi, kondisi, siapa yang menjadi mitra tutur, dan latar belakang mitra tutur, agar mengurangi adanya kesalah pahaman. Seiring dengan perkembangan bahasa bangsa Indonesia, proses komunikasi dari waktu ke waktu banyak mengalami perubahan. Bangsa Indonesia merupakan bangsa yang terkenal dengan sopan santunnya dan condong untuk berbasa-basi saat berkomunikasi. Bahasa indonesia pun mengikuti pola tingkah laku orang Indonesia yang cenderung mengungkapkan dengan secara tidak langsung dalam menyampaikan sesuatu. Sehingga tidak jarang menimbulkan kesalahpahaman dalam memahami maksud dan tujuan yang dituturkan oleh penutur. Maka, perlunya dilakukan penelitian lebih mendalam mengenai tindak tutur yang sering kita jumpai dalam percakapan sehari-hari. Sehingga tidak terjadi kesalahan dalam merespon tuturan yang dituturkan oleh penutur. Kita tidak dapat memungkiri bahwa kesalahpahaman akan sering terjadi dalam komusikasi. Bahkan tidak hanya dengan berkomunikasi secara langsung, komunikasi menggunakan media pun banyak kesalahpahaman yang muncul satu diantaranya media sosial YouTube.

YouTube adalah situs berbagi video yang memberikan kebebasan untuk menyampaikan pendapat dan menunjukkan dunia kepada setiap orang. situs 
YouTube didirikan oleh mantan pekerja PayPal, Steve Chen, Chad Hurley dan Jawed Karim pada 14 Februari 2005. Situs ini memungkinkan pengguna mengunggah, meononton, dan berbagi video (Shalihah, Kompas.com 14 Febuari 2020). Setahun sejak berdirinya, YouTube diakusisi oleh oleh Google seharga US\$ 1,65 miliar. Sejak kemunculan YouTube pada tahun 2006 menjadi situs yang perkembangannya melaju pesat. Dengan diunggahnya video sebanyak 65.000 dan mencapai 100.000 video hinga bulan Juli 2006 ke situs YouTube. Konten YouTube yang bervariasi membuat masyarakat lebih tertarik untuk mengaksesnya. Satu diantaranya konten mengenai Podcast.

Podcast atau dalam bahasa Indonesia Siniar merupakan rekaman audio perepisode yang dapat didengarkan oleh khalayak ramai. Berisi banyak informasi dengan beragam variasi, membuat podcast dikonsumsi oleh kalangan beragam umur untuk menambah pengetahuan tentang banyak hal. Podcast mirip dengan radio karena sama-sama konten berbentuk audio, akan tetapi podcast lebih memiliki banyak genre atau kategori. Kini podcast dapat berbentuk audio visual yang dapat diakses dengan mudah di YouTube.

Youtuber merupakan panggilan untuk kontent kreator atau pembuat video di YouTube. Youtuber di Indonesia yang terkenal akan podcastnya yaitu Deodatus Andreas Deddy Cahyadi Sunjoyo atau lebih dikenal sebagai Deddy Corbuzier. Artis multitalenta Deddy Corbuzier ikut berkecimpung di dunia YouTube sejak 8 Desember 2009. Deddy juga mendapat julukan "Father of YouTube" hingga pertengahan 2020 channelnya telah memiliki 12 juta subscriber, dengan proyeksi pendapatan per bulan USD 30.600,00 atau setara dengan Rp. 428,40 juta. Menjadikan deddy cobuzier Youtuber nomor 3 dengan penghasilan tertinggi di Indonesia (Djumena, Kompas.com 22 Juni 2020). Konten yang paling sering ditonton yaitu Podcast yang acapkali menduduki posisi trending di Indonesia.

Dalam penelitian kali ini, Peneliti memilih Podcast Deddy Cobuzier sebagai objek penelitian. Dari sekian banyak konten podcast Deddy Cobuzier, peneliti memilih episode Natalan Bareng Penista!! Coki Pardede \& Tretan Muslim -Deddy Cobuzier Podcast. Dalam video ini Deddy Cobuzier berkolaborasi dengan youtuber lainnya yaitu Coki Pardede dan Tretan Muslim. Coki Pardede dan Tretan Muslim merupakan youtuber yang cukup kontroversial karena sering membahas hal-hal yang sensitif yang sedang terjadi pada masyarakat saat ini dikemas dengan lawakan khas mereka. Konten-konten tersebut termasuk konten kritis yang jarang dibahas oleh channel lainnya. Video ini telah tonton sebanyak 5.084.388 kali sejak diunggah pada 24 Desember 2020. Dengan pencapaian tersebut, membuat peneliti tertarik untuk meneliti pengambilan alih giliran bicara dalam video yang berdurasi 61 menit 40 detik tersebut.

Penelitian ini mengacu pada pola alih tutur dalam mengambil alih giliran bicara dalam podcast Deddy Cobuzier episode Natalan Bareng Penista!! Coki Pardede \& Tretan Muslim -Deddy Cobuzier Podcast. Selain pembahasan yang menarik, pola alih tutur dalam video tersebut membuat peneliti tertarik untuk mengangkatnya dalam penelitian ini. Interaksi antara penutur dan mitra tutur dalam mengambil alih giliran bicara membuat percakapan tersebut semakin menarik. Terdapat beberapa teknik pengambilan alih giliran bicara yang sebelumnya telah dibahas, akan dibahas secara rinci oleh peneliti dalam penelitian ini. 


\section{METODE PENELITIAN}

Pada penelitian kali ini, peneliti menggunakan metode penelitian deskriptif kualitatif. Penelitian kualitatif lebih mengutamakan proses dari pada hasil. Hal ini disebabkan oleh hubungan antar bagian yang diteliti itu akan menjadi jelas maknanya manakala diamati dalam proses. Menurut Sugiono, penelitian kualitatif adalah penelitian yang menempatkan peneliti sebagai instrumen kunci, teknik pengumpulan data dilakukan secara penggabungan dan analisis data bersifat induktif (Sugiono, 2010:9). Pendapat lainnya mengenai penelitian kualitatif diungkapkan oleh Denzin dan Lincoln (dalam Moleong, 2005:5) penelitian kualitatif adalah penelitian yang menggunakan latar ilmiah, dengan maksud menafsirkan fenomena yang terjadi dan dilakukan dengan melibatkan berbagai metode yang ada. Dalam penelitian ini, peneliti menggunakan metode penelitian kualitatif deskriptif untuk mendeskripsikan fenomena berupa pengambilan pola alih tutur dalam poscast yang saat ini sedang digandrungi oleh sebagian besar pengguna YouTube. Teori yang digunakan untuk mengaji kajian ini yaitu teori pengambilan alih giliran bicara berdasarkan enam teknik yaitu memperoleh, mencuri, merebut, mengganti, menciptakan, dan melanjutkan (Rani, 2006). Oleh karena itu, penelitian ini termasuk ke dalam penelitian kualitatif deskriptif.

Istilah deskriptif menyarankan bahwa penelitian yang dilakukan sematamata hanya berdasarkan pada fakta yang ada atau fenomena yang memang secara empiris hidup pada penutur-penuturnya, sehingga yang dihasilkan atau yang dicatat berupa perian bahasa yang bisa dikatakan sifatnya seperti potret: paparan seperti adanya (Sudaryanto dalam Mustofa, 2010:22). Fakta-fakta yang dideskripsikan dalam penelitian ini meliputi cara pengambilan alih giliran bicara pada poscast Deddy Cobuzier episode Natalan Bareng Penista!! Coki Pardede \& Tretan Muslim-Deddy Cobuzier Poscast. Dengan menggunkan metode penelitian deskriptif kualitatif peneliti akan menggambarkan, menguraikan, dan menjelaskan secara rinci fenomena yang terjadi dalam poscast Deddy Cobuzier episode Natalan Bareng Penista!! Coki Pardede \& Tretan Muslim -Deddy Cobuzier Poscast.

Teknik analisis data dalam penelitian ini dilakukan dengan cara analisis data deskriptif kualitatif, karena data yang dihasilkan berupa dialog percakapan narasumber dalam poscast milik deddy cobuzier. Menurut Moleong (2002:103) analisis data adalah proses mengatur urutan data, mengorganisasikanya ke dalam suatu pola, kategori, dan satuan uraian dasar.

\section{HASIL DAN PEMBAHASAN \\ Pola Alih Tutur Giliran Bicara Dalam Podcast Deddy Cobuzier Episode Natalan Bareng Penista!! Coki Pardede \& Tretan Muslim}

Terjadinya peralihan tutur merupakan syarat percakapan yang penting, karena peralihan tutur ini akan menimbulkan pergantian peran antara pembicara dan pendengar. Peneliti akan mendeskripsikan jenis-jenis pola alih tutur dalam mengambil alih giliran bicara pada podcast milik Deddy Cobuzier. Jenis-jenis pengambilan alih giliran bicara dalam podcast tersebut akan dibagi menjadi enam teknik yaitu memperoleh (1), mencuri (2), merebut (3), mengganti (4), menciptakan (5), dan melanjutkan (6). Berikut pembahasannya. 


\section{Memperoleh}

Memperoleh giliran bicara merupakan suatu cara mengambil giliran bicara yang diberikan oleh pembicara terdahulu. Dalam hal ini, pembicara terdahulu memberikan kesempatan bicara pada mitra tuturnya agar segera mengambil alih giliran bicara (Rani, 2006:215). Cara ini ditandai dengan pembicara terdahulu memberikan kesempatan kepada mitra tuturnya untuk melanjutkan pembicaraan.

Teknik memperoleh biasanya ditandai dengan diamnya pembicara terdahulu sehingga pembicara selanjutnya bisa mengambil alhi giliran bicara. Teknik ini dapat dilihat dalam percakapan yang melibatkan tanya jawab didalamnya. Pembicara dahulu biasanya memberikan pertanyaan, sehingga membuat mitra tuturnya segera mengambil alih giliran bicara untuk melanjutkan pembicaraan. Teknik mengambil alih giliran bicara dengan cara memperoleh dapat dilihat pada podcast Deddy Cobuzier Episode Natalan Bareng Penista!! Coki Pardede \& Tretan Muslim berikut contoh kutipan dan penjelasannya.

1) Coki Pardede : "apakah itu it's an honor buat lo? Atau lo terganggu?"

Deddy Corbuzier : "it's an honor bos ada orang bikin tatto close the door di perutnya"

Tretan Muslim : "kenapa close the door? kenapa kalo mengidolakan ente nggak muka ente gitu maksudnya?"

Coki Pardede : : "karena dia tahu yang bagus programnya bukan orangnya"

(Lamp1/1340/MPH)

Penggalan percakapan data 1) di atas merupakan satu diantara banyaknya kutipan percakapan yang menggunakan teknik memperoleh dalam podcast Deddy Cobuzier Episode Natalan Bareng Penista!! Coki Pardede \& Tretan Muslim. Dapat dilihat penutur utama yaitu Coki Pardede menyampaikan sebuah pertanyaan kepada mitra tuturnya. Menanggapi pertanyaan tersebut, mitra tuturnya yaitu Deddy Corbuzier segera mengambil alih kesempatan dengan mengutarakan pendapatnya mengenai ujaran penutur sebelumnya yaitu Coki Pardede. Giliran bicara kembali berlanjut saat Tretan Muslim memberikan pertanyaan lainnya kepada mitra tuturnya, namun masih dalam konteks topik yang sama dengan sebelumnya. Hal tersebut kembali ditanggapi oleh mitra tuturnya yaitu Coki Pardede. Pola alih tutur di atas termasuk ke dalam pengambilan alih giliran bicara dengan teknik memperoleh. Coki Pardede dan Tretan Muslim memberikan kesempatan pada mitra tutunya untuk mengambil alih giliran bicara dengan memberikan pertanyaan kepada mitra tuturnya. Hal ini ditandai dengan diamnya penutur sebelumnya setelah menyelesaikan ujarannya.

Kutipan percakapan lainnya yang mengganakan teknik mengambil alih giliran bicara dengan teknik memperoleh yaitu berikut ini.

2) Deddy Corbuzier : "pake nanya kenape-kenape, ini aja nggak kuning dollar nya aja udah syukur"

Coki Pardede : "jadi buat lo yang ngerasa om Deddy itu memanfaatkan

momentum memanfaatkan apapun untuk kepentingan itu sebenarnya not completely true karena memang 


\section{ada dollar kuning akhirnya zonk aja, lo bahkan nggak dapat keuntungan sama sekali" \\ Deddy Corbuzier : "nggak dapat apa-apa" \\ Coki Pardede : "bahkan dapat hujatannya kan?" \\ Deddy Corbuzier : "oh iya bener"}

(Lamp1/500/MPH)

Kutipan percakapan yang bercetak tebal di atas merupakan contoh pengambilan alih giliran bicara dengan teknik memperoleh yang terdapat dalam podcast Deddy Cobuzier Episode Natalan Bareng Penista!! Coki Pardede \& Tretan Muslim. Kutipan pertama yang bercetak tebal menunjukkan pembicara terdahulu yaitu Coki Pardede memberikan kesempatan berbicara kepada mitra tuturnya untuk mengonfirmasi penjelasannya. Hal tersebut ditandai dengan diamnya Coki Pardede setelah menyelesaikan ujarannya. Melihat tanda tersebut Deddy Corbuzier sebagai subjek yang dibicarakan mengambil alih giliran bicara dengan memberikan tanggapannya. Teknik mengambil alih giliran bicara dengan cara memperoleh lainnya dapat dilihat pada penggalan kutipan di atas yaitu penggalan kedua percakapan yang bercetak tebal. Coki Pardede kembali memberikan kesempatan berbicara kepada mitra tuturnya yaitu Deddy Corbuzier, hal tersebut dilakukan Coki Pardede dengan melemparkan pertanyaan kepada mitra tuturnya Deddy Corbuzier untuk kembali menekankan ujarannya sebelumnya. Deddy Corbuzier kembali mengambil alih giliran bicara setelah mendapatkan pertanyaan dari Coki Pardede. Kutipan penggalan tersebut menunjukkan cara mengambil alih gilran bicara dengan teknik memperoleh. Dimana penutur sebelumnya memberikan kesempatan mitra tuturnya untuk mengambil alih gilirian bicara dengan tanda diamnya penutur sebelumnya.

\section{Mencuri}

Mencuri giliran bicara merupakan cara mengambil alih giliran bicara pada waktu pembicara terdahulu belum selesai berbicara, tetapi ia dalam keadaan lengah (Rani, 2006:216). Hal ini ditandai dengan mitra tutur memberikan tanggapan kepada penutur, saat penutur tidak memperkirakan bahwa mitra tutur akan mengambil alih giliran bicara. Teknik mengambil alih giliran bicara dengan cara memperoleh dapat dilihat pada podcast Deddy Corbuzier Episode Natalan Bareng Penista!! Coki Pardede \& Tretan Muslim berikut beberapa penggalan kutipan dan penjelasannya.

3) Coki Pardede : "jadi kita ak...kita mulai dari yang simple-simple"

Tretan Muslim : "ya"

Coki Pardede : "gimana kabar om Deddy?"

Deddy Corbuzier : "ya belakangan ini baik-baik aja cuman memang kalo melihat keadaan indonesia saat ini"

Coki Pardede : "ya!"

Deddy Corbuzier : "ngeliat berita terkejut juga hati, sedih juga hati kenpa biasa terjadi seperti ini? Sedangkan mau saya bawa ke podcast masalahnya, tapi anyep-anyep sedep juga serem gitu kan"

(Lamp2/180/MCI) 
Kutipan di atas dikategorikan sebagai contoh pengambilan alih giliran bicara dengan teknik mencuri dalam podcast Deddy Corbuzier Episode Natalan Bareng Penista!! Coki Pardede \& Tretan Muslim. Hal tersebut ditunjukkan dengan beberapa kutipan kalimat yang bercetak tebal di atas. Pada kalimat yang bercetak tebal bagian pertama, ujaran milik Tretan Muslim merupakan ujaran yang terjadi dengan alih tutur mencuri, ujaran tersebut diucapkan saat Coki Pardede masih melanjutkan ujarannya dan Coki Pardede tidak menduga bahwa Coki Pardede akan mengambil giliran bicara. Penggalan percakapan di atas juga terdapat kutipan kalimat milik Coki Pardede yang melakukan teknik mengambil alih giliran bicara dengan cara mencuri. Bagian tersebut ditunjukkan oleh kalimat yang bercetak tebal kedua milik Coki Pardede. Pada saat Deddy Corbuzier masih menggunakan giliran bicara miliknya, Coki Pardede mengambil alih giliran bicara milk Deddy Corbuzier dengan memberikan sahutan dari kalimat yang diujarkan oleh Deddy Corbuzier, dan Deddy Corbuzier tidak menyangka bahwa Coki Pardede akan mengambil alih giliran bicara tersebut. Oleh karena itu, penggalan percakakan di atas termasuk ke dalam cara mengambil alih giliran bicara dengan teknik mencuri.

Kutipan di bawah ini juga menunjukkan penggunaan cara mengambil alih giliran bicara dengan teknik mencuri, berikut penjelasannya.

4) Coki Pardede : "tapi dengan membuat definisi-definisi seperti ini Tretan Muslim ingin menginternasionalkan sarung"

Tretan Muslim : "bener"

Coki Pardede : "dengan desain-desain yang ege...."

Tretan Muslim : "yang modern"

Coki Pardede : "yang modern ini kebetulan cyberpunk"

(Lamp2/1620/MCI)

Penggalan percakapan data 4) di atas termasuk ke dalam mengambil alih giliran bicara dengan teknik mencuri. Coki Pardede merupakan penutur terdahulu sedangkan Tretan Muslim merupakan mitra tuturnya. Pada kutipan data 4) di atas, Tretan Muslim selaku mitra tutur mengambil alih giliran bicara dengan teknik mencuri, disaat Coki Pardede sebagai penutur terdahulu melakukan jeda untuk menemukan kata yang yang tepat, akan tetapi Tretan Muslim sebagai mitra tutur mengambil alih giliran bicara, disaat keadaan penutur sebelumnya atau Coki Pardede lengah. Oleh karena itu, kutipan di atas termasuk ke dalam teknik mengambil alih giliran bicara dengan cara mencuri.

\section{Merebut}

Merebut merupakan cara mengambil alih giliran bicara pada saat pembicara terdahulu sedang berbicara dan masih ingin melanjutkannya (Rani, 2006:216). Cara ini terjadi karena spontanitas dari mitra tuturnya untuk mengungkapkan pendapat atau memberikan tanggapan.

5) Deddy Corbuzier : "gara-gara lu gue nggak jadi bikin video ama anak gue padahal gue udah janji ama anak gue jam tujuh bikin video, gue harus pergi ama anak gue jam tujuh ternyata lo datang telat-telat, lo datang kenapa pakai topi natal?"

Tretan Muslim : "ini kan menghormati..." 


\section{Coki Pardede : "menghormati!"}

Tretan Muslim :"menghormati yang natal, kan biasanya di razia ...."

(Lamp3/10/MRT)

Penggalan percakapan data 5) di atas menunjukkan penggunaan teknik mengambil alih giliran bicara dengan cara merebut. Pergantian tutur dengan teknik merebut dapat dilihat pada kalimat yang bercetak tebal di atas. Tretan Muslim selaku penutur sebelumnya mengambil alih giliran bicara yang diberikan oleh Deddy Corbuzier sebagai mitra tutur, saat sedang menggunakan giliran tuturnya, Coki Pardede sebagai mitra tutur dari Tretan Muslim mengambil giliran alih bicara milik Tretan Muslim dengan cara merebut. Hal tersebut dapat dilihat pada kalimat yang bercetak tebal di atas. Tretan Muslim kembali mengambil alih giliran bicara yang direbut oleh Coki Pardede sebelumnya dengan cara melanjutkan kembali ucapannya yang sempat terjeda. Oleh karena itu penggalan percakapan Coki Pardede di atas termasuk ke dalam mengambil alih giliran bicara dengan cara merebut.

Kutipan lainnya pada podcast Deddy Corbuzier Episode Natalan Bareng Penista!! Coki Pardede \& Tretan Muslim yang menggunakan teknik merebut dalam pengambilan alih giliran bicara dapat dapat dilihat di bawah ini.

6) Coki Pardede : "Gue selalu ngerasa it's an honor ada di sebuah platform yang ...."

Deddy Corbuzier : "jangan mulai!"

Coki Pardede : "nggak bener loh, nggak kita tidak bilang bagus atau nggak kan ya, ya karna itu kan subjektif"

(Lamp3/50/MRT)

Kutipan data 6) di atas merupakan bagian dari teknik menerebut dalam pengambilan alih giliran bicara pada podcast Deddy Corbuzier Episode Natalan Bareng Penista!! Coki Pardede \& Tretan Muslim. Penggalan kalimat yang menunjukkan penggunaan teknik merebut pada data 6) ditunjukkan dengan kalimat yang bercetak tebal di atas. pada percakapan di atas Coki Pardede berperan sebagai penutur sebelumnya, saat sedang menggunakan giliran bicara miliknya, Deddy Corbuzier mengambil alih giliran bicara milik Coki Pardede dengan teknik merebut. Setelah menyelesaikan ucapannya, Coki Pardede kembali merebut giliran bicara miliknya yang sebelumnya direbut oleh Deddy Corbuzier. Maka dari itu, penggalan percakapan di atas merupakan bagian dari penggunaaan pengambilan alih giliran bicara dengan teknik merebut yang terdapat pada podcast Deddy Corbuzier Episode Natalan Bareng Penista!! Coki Pardede \& Tretan Muslim.

\section{Mengganti}

Mengganti merupakan cara mengambil alih giliran bicara dengan cara mengganti atau melanjutkan bicara mitra tuturnya karena mitra tuturnya tidak mampu meneruskan bicara (Rani, 2006:217). Mengambil alih giliran bicara dengan cara mengganti dimaksudkan untuk mempertahankan percakapan. Berikut penjelasan mengenai pola alih tutur pengambilan alih giliran bicara dengan teknik mengganti yang terdapat dalam podcast Deddy Corbuzier Episode Natalan Bareng Penista!! Coki Pardede \& Tretan Muslim. 
Penggalan percakapan di atas merupakan contoh pengambilan alih giliran bicara dengan teknik mengganti yang terdapat dalam podcast Deddy Corbuzier Episode Natalan Bareng Penista!! Coki Pardede \& Tretan Muslim. Hal tersebut ditunjukan dengan kalimat yang bercetak tebal di atas, yang berupa lanjutan dari ujaran Coki Pardede yaitu mitra tutur Deddy Corbuzier. Dalam penggalan percakapan di atas Deddy Corbuzier kembali menyinggung mengenai ujaran yang dituturkan mitra tuturnya sebelumnya. Dalam tuturannya, Coki Pardede pada baris pertama penggalan kutipan menyampaikan kata "rezeki", untuk memperjelas kata tersebut Deddy Corbuzier mengambil alih giliran bicara dengan teknik mengganti ujarannya milik mitra tuturnya kea rah yang lebih spesifik dengan pokok bahasan mereka sebelumnya. Oleh karena itu, penggalan percakapan di atas termasuk ke dalam pengambilan alih giliran bicara dengan teknik mengganti.

Kutipan lainnya yang menunjukkan teknik pengambilan alih giliran bicara dengan cara mengganti yang terdapat dalam podcast Deddy Corbuzier Episode Natalan Bareng Penista!! Coki Pardede \& Tretan Muslim, berikut ini pembahasannya.

8) Deddy Corbuzier : "ya apa mau diklarifikasiin?"

Tretan Muslim : "bukan! Anda kemarin saya mengikuti kasus sebuah kasus a ...."

Coki Pardede : "itu bukan kasus bahkan"

Tretan Muslim : "bukan kasus tapi ya bisa ...."

Coki Pardede : "misunderstanding sih menurut gue"

Tretan Muslim : "misunderstanding katanya ente menyindir ...."

Coki Pardede : "seseorang"

Tretan Muslim : "ya menyindir seseorang katanya mau diundang terus dia nyindir balik di kontennya"

(Lamp4/240/MGT)

Data 8) merupakan bagian dari podcast Deddy Corbuzier Episode Natalan Bareng Penista!! Coki Pardede \& Tretan Muslim yang menggunakan teknik pengambilan alih giliran bicara dengan teknik mengganti. Pada setiap giliran bicara yang dituturkan penutur, penutur selalu melanjutkan giliran bicara dengan pokok bahasan yang merupakan lanjutan dari ujaran sebelumnya. Dapat dilihat pada penggalan percakapan di atas di baris kedua, Tretan Muslim berperan sebagai penutur sebelumnya mengeluarkan kata "kasus" pada kalimatnya, selanjutnya Coki Pardede yang merupakan mitra tutur Tretan Muslim menggunakan giliran tuturnya dengan menegaskan kembali kata "kasus" dengan mengganti kalimat tersebut. Pengambilan alih giliran bicara dengan teknik mengganti juga dapat dilihat pada pergantian penutur berikutnya. Seperti yang 
dapat dilihat pada penggalan percakapan di atas, Tretan Muslim menggunakan teknik mengganti untuk memperjelas ujaran mitra tutur sebelumnya yitu Coki Pardede, pada kata "misunderstanding" dengan mengganti kalimat mitra tutrnya agar menjadi lebih jelas. Hal tersebut dilakukan untuk mempertahankan percakapan agar sesuai dengan topik yang dibicarakan. Maka dari itu, penggalan percakapan di atas termasuk ke dalam pengambilan alih giliran bicara dengan teknik mengganti.

\section{Menciptakan}

Menciptakan merupakan pengambilan alih giliran bicara dengan cara menciptakan inisiasi atau reinisisasi sehingga tercipta pertukaran baru atau berikutnya (Rani, 2006:217). Mitra tutur biasanya menciptakan tuturan baru yang berbeda tetapi masih berkaitan dengan tuturan sebelumnya. Dalam podcast Deddy Corbuzier Episode Natalan Bareng Penista!! Coki Pardede \& Tretan Muslim terdapat beberapa penggalan percakapan yang menggunakan teknik menciptakan dalam pengambilan alih giliran bicara. Berikut penjelasan beberapa penggalan percakapan tersebut.

9) Coki Pardede : "setidaknya ke elo untuk atas nama orang-orang itu, kita gue pengen bilang thank you karna kadang gini om Deddy tuh lu ngebawain apa sih? Enggak dia punya semua, fame, duit apa segala macam dia udah punya semua, kadang yang harus kita kasih ke om Deddy itu just small kestrel thank you“"

Deddy Corbuzier : "gila ini...."

Coki Pardede : "iya dong, bener dong?"

Deddy Corbuzier : "inspiratif"

Coki Pardede : "bener dong-bener dong"

Deddy Corbuzier : "kayak acaranya Robby Purba ini"

Coki Pardede : "uwahhh!"

Tretan Muslim : "setara robby purba"

(Lamp5/540/MCOKI PARDEDE )

Penggalan percakapan data 9) di atas menggunakan teknik pengambilan alih giliran bicara dengan cara mengganti. Hal tersebut ditunjukkan pada penggalan kutipan kalimat yang bercetak tebal di atas. kutipan kalimat yang bercetak tebal milik Deddy Corbuzier di atas merupakan tuturan baru sebagai respon dari tuturan yang sebelumnya. Cara ini dimaksudkan untuk mengarahkan pada ujaran sebelumnya, yaitu talkshow yang saling menghargai dengan mengucapkan terima kasih. Kutipan kalimat yang bercetak tebal di atas merupakan tuturan baru yang masih mengarah pada topik yang sama, namun memberikan contoh yang masih serupa. Oleh karena itu, penggalan percakapan di atas termasuk ke dalam pengambilan alih giliran bicara dengan teknik menciptakan.

\section{Melanjutkan}

Melanjutkan merupakan cara mengambil alih giliran bicara berikutnya karena mitra tuturnya tidak memanfaatkan kesempatan yang diberikan. 
Mengambil giliran bicara dengan cara tersebut dilakukan apabila mitra tutur yang diberi kesempatan berbicara tidak segera mengambil (Rani, 2006:218). Berikut pembahasan mengenai penggunaan teknik mengambil alih giliran bicara dengan cara melanjutkan.

$$
\begin{array}{ll}
\text { Coki Pardede } & : \text { "fame exhausted" } \\
\text { Deddy Corbuzier } & \text { "sorry-sorry there's another question melelahkan } \\
\text { atau menakutkan?" } & \\
\text { Coki Pardede } & \text { "ya dua-duanya, lo lelah nggak dengan ketenaran } \\
\text { Deddy Corbuzier } & \text { : "..." } \\
\text { Coki Pardede } & : \text { kayanya hampir semua orang di Indonesia hampir } \\
& \text { tahu lah ... hampir semua tahu Deddy Corbuzier itu } \\
& \text { melelahkan gak buat lo di situ itu pertanyaan } \\
& \text { pertama buat lo, yang kedua dan menakutkan } \\
& \text { nggak?" }
\end{array}
$$

Data 10) di atas yaitu penggalan percakapan yang terdapat dalam podcast Deddy Corbuzier Episode Natalan Bareng Penista!! Coki Pardede \& Tretan Muslim, yan menggunkan teknik melanjutkan dalam pengambilan alih giliran bicara. Data di atas menunjukkan ketidakmampuan mitra tutur dari Coki Pardede, yaitu Deddy Corbuzier dalam mengambil alih giliran bicara. Pada penggalan percakapan di atas, pada baris keempat Coki Pardede memberikan sebuah pertanyaan kepada Deddy Corbuzier yang merupakan mitra tutur dari Coki Pardede. Deddy Corbuzier tidak memanfaatkan kesempatan berbicara untuk menjawab pertanyaan dari penutur sebelumnya. Melihat mitra tuturnya tidak memberikan respon, Coki Pardede kembali mengambil alih giliran bicara dengan melanjutkan penjelasannya dan memberikan pertanyaan. Pola alih tutur tersebut merupakan teknik mengambil alih giliran bicara dengan melanjutkan, dimana Coki Pardede melanjutkan pembicaraan saat ia memberikan kesempatan berbicara kepada mitra tuturnya, namun mitra tuturnya tidak memberikan respon.

\section{SIMPULAN}

Penelitian ini berfokus pada pola tutur pengambilan alih giliran bicara yang terdapat dalam podcast Deddy Cobuzier Episode Natalan Bareng Penista!! Coki Pardede \& Tretan Muslim. Dalam podcast Deddy Corbuzier tersebut terdapat tiga orang penutur yang terlibat dalam sebuah dialog panjang yaitu Deddy Corbuzier, Coki Pardede, dan Tretan Muslim. pada penelitian ini, teknik pengambilan alih giliran bicara terbagi ke dalam enam bentuk yaitu memperoleh, mencuri, merebut, mengganti, menciptakan, dan melanjutkan. Masing-masing teknik pengambilan alih giliran bicara tersebut terdapat dalam podcast Deddy Cobuzier Episode Natalan Bareng Penista!! Coki Pardede \& Tretan Muslim. 


\section{DAFTAR PUSTAKA}

Baryadi, Pratomo. 2002. Dasar-dasar Analisis Wacana dalam bahasa.

Yogyakarta: Pustaka ganda Suli.

Djumena, Airlangga. 2020 "Ini 10 Youtuber Indonesia dengan Penghasilan Tertinggi". Kompas.com Edisi 22 Juni https://money.kompas.com/ read/2020/06/22/050300626/ini-10-youtuber-Indonesia-denganpenghasilan-tertinggi-?page=all. Diakses pada 16 Febuari 2021.

Moleong, Lexy J. 2007. Metodologi Penelitian Kualitatif. Edisi Revisi. Bandung : PT Remaja Rosdakarya

Mulyana Deddy. 2005. Ilmu Komunikasi Suatu Pengantar. Bandung: PT Remaja. Rosdakarya.

Mustofa. 2010. Model Pendidikan Dan Pelatihan (Konsep dan Aplikasi). Bandung: Penerbit Alfabeta.

Rani, Abdul. 2006. Analisis Wacana Sebuah Kajian Bahasa dalam. Pemakaian. Malang: Bayu Media Publishing.

Shalihah, Nur Fitriatu. 2020. "Hari Ini dalam Sejarah: YouTube Diluncurkan, Bagaimana Awal Mulanya?". Kompas.com Edisi 14 Febuari. https://www.kompas.com/tren/read/2020/02/14/080500565/hari-inidalam-sejarah--youtube-diluncurkan-bagaimana-awal-mulanya?page $=$ all. Diakses pada 16 Febuari 2021.

Tarigan, Henry Guntur. 2009. PengkajianPragmatik. Bandung: Angkasa

Sugiyono. 2010. Metode Penelitian Pendidikan Pendekatan Kuantitatif, kualitatif, dan $R \& D$. Bandung: Alfabeta. 